\title{
THE C-13 NMR SPECTRUM OF NOVOBIOCIN
}

\author{
LESTER DOLAK \\ The Upjohn Company, Kalamazoo, Michigan 49001, U.S.A. \\ (Received for publication April 22, 1976)
}

\begin{abstract}
The carbons of novobiocin have been assigned to peaks in the CMR spectrum on the basis of chemical shifts and off-resonance experiments on novobiocin and related compounds.
\end{abstract}

Novobiocin was the first isolated member of a family of antibiotics. Chlorobiocin ${ }^{1)}$ and coumermycin $^{2)}$ were isolated at a later date and have not been used clinically. Since CMR spectroscopy has proved useful in biogenetic ${ }^{3)}$ and structural ${ }^{4)}$ work we now report our assignment of the C-13 spectrum of novobiocin. The CMR spectra of erythromycins, ${ }^{5)}$ rifamycins ${ }^{8)}$ and aminoglycosides ${ }^{(7)}$ have been assigned by others.

Fig. 1. Novobiocin

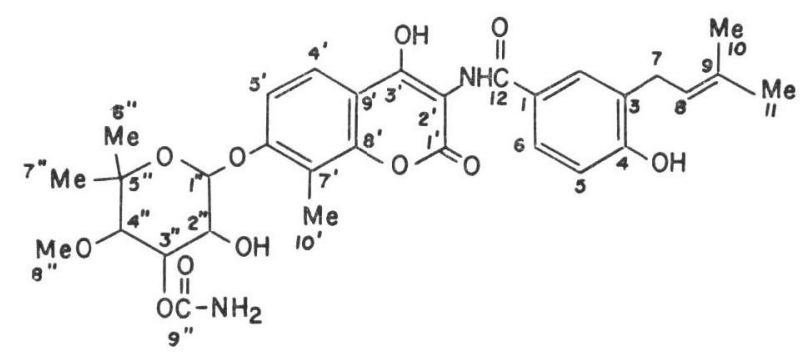

All spectra reported here were obtained on a Varian CFT-20. Multiplicities were determined using off-resonance techniques according to the manufacturer's instructions. For convenience, the carbons are numbered as in Fig. 1.

The anomeric, carbamyl, gem-dimethyl and methoxyl carbons (C-1", 9", 6", $7^{\prime \prime}$ and $\left.8^{\prime \prime}\right)$ were easily assigned on the basis of chemical shift and multiplicity data (Table 1) on ethyl novioside ${ }^{8)}$ (I). Carbons $2^{\prime \prime}, 3^{\prime \prime}$ and $4^{\prime \prime}$ were assigned using a relationship between residual splittings and proton chemical shifts described by BIRDSALL ${ }^{9)}$

Four of the carbons in the isopentenyl side chain in 4-hydroxy-3-(3-methyl-2-butenyl)-benzoic

Fig. 2. Calculated $v s$ observed shifts for II

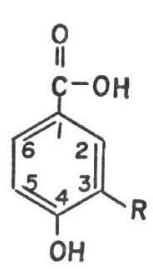

\begin{tabular}{c|c|c}
\hline \multicolumn{3}{c}{ Shift } \\
\hline Carbon \# & Calculated & Observed \\
\cline { 1 - 2 } 1 & 123.2 & 121.6 \\
2 & 132.1 & 131.2 \\
3 & 124.7 & 127.7 \\
4 & 161.2 & 159.5 \\
5 & 115.7 & 114.7 \\
6 & 128.5 & 129.1 \\
\hline
\end{tabular}


acid $^{8)}$ (II) were assigned in analogy to 2-methyl-2-butene. ${ }^{10)}$ Furthermore, the doublet at $\delta 122.5$ and the singlet at $\delta 131.9$ disappear on hydrogenation over platinum. ${ }^{8}$ ) The carbons in the benzene ring were assigned using the additivity of substituent effects ${ }^{4)}$ as shown in Fig. 2 (assuming $\mathrm{R}=$ methyl).

The carbons of the coumarin ring presented the most difficulty due to the seven quaternary carbons and their overlap with the carbons of the benzamido ring. We prepared novobiocic

Table 1. The $\mathrm{C}-13$ chemical shifts for novobiocin and related compounds ${ }^{1)}$

\begin{tabular}{|c|c|c|c|c|c|c|c|}
\hline Carbon \# & Novobiocin & $\mathbf{I}^{2)}$ & II & IIII $^{3)}$ & IV & $\mathbf{V}^{4)}$ & $\mathbf{V I}^{5)}$ \\
\hline 1 & 123.6 & & 121.6 & 123.7 & & & \\
\hline 2 & $129.9 \mathrm{~d}$ & & $131.2 \mathrm{~d}$ & $129.9 \mathrm{~d}$ & & & \\
\hline 3 & 127.6 & & 127.8 & 127.7 & & & \\
\hline 4 & $158.8^{*}$ & & 159.5 & 158.9 & & & \\
\hline 5 & $114.6 \mathrm{~d}$ & & $114.8 \mathrm{~d}$ & $114.6 \mathrm{~d}$ & & & \\
\hline 6 & $127.6 \mathrm{~d}$ & & $129.2 \mathrm{~d}$ & $127.5 \mathrm{~d}$ & & & \\
\hline 7 & $28.5 \mathrm{t}$ & & $28.0 \mathrm{t}$ & & & & \\
\hline 8 & $122.5 \mathrm{~d}$ & & $122.5 \mathrm{~d}$ & $122.6 \mathrm{~d}$ & & & \\
\hline 9 & 131.7 & & 131.9 & 131.7 & & & \\
\hline 10 & $17.7 q$ & & $17.6 \mathrm{q}$ & $17.7 \mathrm{q}$ & & & \\
\hline 11 & $25.5 \mathrm{q}$ & & $25.6 \mathrm{q}$ & $25.6 \mathrm{q}$ & & & \\
\hline 12 & $167.0^{1}$ & & $167.8^{1}$ & 167.1 & & & \\
\hline $1^{\prime}$ & $158.2^{*}$ & & & 159.2 & 160.5 & 157.3 & 162.3 \\
\hline $2^{\prime}$ & 101.9 & & & 101.0 & 100.9 & 124.1 & $91.4 \mathrm{~d}$ \\
\hline $3^{\prime}$ & 160.7 & & & 161.0 & 161.3 & $128.5 \mathrm{~d}$ & 165.9 \\
\hline $4^{\prime}$ & $121.9 \mathrm{~d}$ & & & $121.6 \mathrm{~d}$ & $121.9 \mathrm{~d}$ & $123.3 \mathrm{~d}$ & \\
\hline $5^{\prime}$ & $110.3 \mathrm{~d}$ & & & $112.1 \mathrm{~d}$ & $110.3 \mathrm{~d}$ & $109.7 \mathrm{~d}$ & \\
\hline $6^{\prime}$ & $157.1^{*}$ & & & 158.3 & 157.2 & 149.9 & \\
\hline $7^{\prime}$ & 110.3 & & & 110.6 & 110.0 & $119.0 \mathrm{~d}$ & \\
\hline $8^{\prime}$ & 150.4 & & & 151.2 & 150.8 & 151.0 & 153.8 \\
\hline $9^{\prime}$ & 113.0 & & & 108.3 & 113.0 & 117.4 & 116.1 \\
\hline $10^{\prime}$ & $8.3 q$ & & & $8.1 \mathrm{q}$ & $8.3 q$ & & \\
\hline $1^{\prime \prime}$ & $98.7 \mathrm{~d}$ & $100.9 \mathrm{~d}$ & & & $98.6 \mathrm{~d}$ & & \\
\hline $2^{\prime \prime}$ & $69.0 \mathrm{~d}$ & $69.6 \mathrm{~d}$ & & & $69.0 \mathrm{~d}$ & & \\
\hline $3^{\prime \prime}$ & $70.7 \mathrm{~d}$ & $70.9 d$ & & & $70.7 \mathrm{~d}$ & & \\
\hline $4^{\prime \prime}$ & $81.1 \mathrm{~d}$ & $81.3 \mathrm{~d}$ & & & $81.0 \mathrm{~d}$ & & \\
\hline $5^{\prime \prime}$ & 78.3 & 78.8 & & & 78.3 & & \\
\hline $6^{\prime \prime}$ & $28.2 q$ & $28.3 q^{* *}$ & & & $28.5 q^{* *}$ & & \\
\hline $7^{\prime \prime}$ & $22.8 \mathrm{q}$ & $22.5 \mathrm{q}^{* *}$ & & & $22.8 q^{* *}$ & & \\
\hline $8^{\prime \prime}$ & $61.0 \mathrm{q}$ & $61.0 \mathrm{q}$ & & & $61.1 \mathrm{q}$ & & \\
\hline $9^{\prime \prime}$ & $156.5^{*}$ & 156.5 & & & $156.5^{1}$ & & \\
\hline
\end{tabular}

* These four are indistinguishable from each other.

** Indistinguishable from each other.

1) The peaks are singlets except where labelled $\mathrm{q}$, $\mathrm{t}$ or $\mathrm{d}$ for quartet, triplet and doublet. All spectra done on the Varian CFT-20 in $\mathrm{d}_{8}$-DMSO. Shifts are given in parts per million relative to internal TMS. The multiplicities were determined using off-resonance experiments.

2) Also, peaks at $62.3 \mathrm{t}$ and $14.8 \mathrm{q}$ for the ethoxyl carbons.

3) Also, peaks at $155.7,60.7 \mathrm{t}$ and $14.6 \mathrm{q}$ for the carbamyl and ethoxyl carbons.

4) Also, peaks at $170.2,168.9,23.9 \mathrm{q}$ and 20.8 for the acetyl carbons.

5) Also, unassigned doublets at 132.5, 123.8, 123.4 and 116.4. 
<smiles>[M]C1(C)OC(OCC)C(O)C(C(N)=O)C1OC</smiles><smiles>CC(C)=CCc1cc(C(=O)O)ccc1O</smiles>

II<smiles>CCOC(=O)Nc1c(O)c2ccc(OC3OC(C)(C)C(OC)C(OC(N)=O)C3O)c(C)c2oc1=O</smiles><smiles>CC(=O)Nc1cc2ccc(OC(C)=O)cc2oc1=O</smiles><smiles>O=c1cc(O)c2ccccc2o1</smiles>

Vi

acid $^{8)}$ (III), ethoxycarbonyl-novenamine ${ }^{11)}$ (IV) and 3-acetamido-7-acetoxycoumarin ${ }^{12)}$ (V) and purchased 4-hydroxycoumarin (VI) to facilitate the assignments. The CMR spectrum of coumarin has been published. ${ }^{10}$

The $10^{\prime}$ carbon is common to III and IV at $\delta 8.2$. The farthest down-field singlets in III are the $1^{\prime}, 3^{\prime}, 6^{\prime}$ and $8^{\prime}$ carbons. The $3^{\prime}$ carbon was assigned to the peak at $\delta 161.0$ due to its shift to $\delta 166$ in the spectrum of novobiocin when sodium bicarbonate was added to the solution. The shifts for other carbons were considerably smaller. The $8^{\prime}$ carbon is assignable due to its consistent position in all the model compounds. We consider the $4,1^{\prime}, 6^{\prime}$, and $9^{\prime \prime}$ carbons indistinguishable but have given them reasonable assignments in Table 2 based on the models. The assignment of $\mathrm{C}-2^{\prime}$ in VI was based on the expected upfield shift due to ketoenol tautomerism relative to its position in other models. Removal of this effect in $\mathbf{V}$ combined with amination results in a new singlet at $\delta 124.1$. Reintroduction of the effect in IV results in an upfield shift of the $\mathrm{C}-2^{\prime}$ carbon relative to its shift in $\mathbf{V}$.

The unassigned doublets in VI at $\delta 132$ and $\delta 123$ give rise to doublets at $\delta 119$ and $\delta 109$ in V. These must be due to the $5^{\prime}$ and $7^{\prime}$ carbons because of the expected upfield shift ${ }^{4)}$ of carbons ortho to an oxygen. One of the remaining two doublets in VI is due to C-4' and so should be relatively unaffected by the further substitutions made. This can only be the doublet at $\delta 123$. By difference the doublet at $\delta 116.4$ is assignable to the $6^{\prime}$ carbon. This doublet disappears on oxygenation to give $\mathbf{V}$.

Methylation of C-7' should give rise to a new singlet $9 \mathrm{ppm}$ downfield from its position in V. Only the doublet at $\delta 119$ does this so we assign it to C-7'. Therefore, the peak at 
$\delta 109$ must be assigned to the $5^{\prime}$ carbon. The remaining singlet in $\mathbf{V}$ at $\delta 117$ must be due to C-9'.

\section{Acknowledgments}

The author acknowledges useful discussions with K. RINEHART (University of Illinois) and S. Mizsak, and the technical assistance of R. Reid and D. Squires.

\section{References}

1) Dolak, L.: The structure of RP 18,631. J. Antibiotics 26: 121 125, 1973

2) Kawaguchi, H.; H. Tsukiura \& M. Okanishi: Studies on coumermycin, a new antibiotic. I. Production, isolation and characterization of coumermycin $\mathbf{A}_{1}$. J. Antibiotics, Ser. A 18:1 10, 1965

3) Sequin, U. \& A. I. Scott: Carbon-13 as a label in biosynthetic studies. Science 186: 101 107, 1974

4) Levy, G. C. \& G. L. Nelson: Carbon-13 nuclear magnetic resonance for organic chemists. WileyInterscience, 1972

5) Terui, Y.; K. Tori, K. Nagashima \& N. Tsuji: C-13 Nuclear magnetic resonance spectra of erythromycins. Tetrahedron Lett. 1975; 2583 2586, 1975

6) Martinelli, E.; R. J. White \& G. G. Gall: Carbon-13 NMR spectra of rifamycin. Tetrahedron 29: $3441 \sim 3448,1973$

7) Yamaoka, Y.; T. Usui, H. Sugiyama \& S. Seto: C-13 NMR spectra of some aminosugars and sugar-antibiotics, neomycin and kanamycin. Chem. Pharm. Bull. 22: 2196 2200, 1974

8) Hinman, J. W.; E. L. Caron \& H. Hoeksema: The structure of novobiocin. J. Am. Chem. Soc. 79: 3789 3800, 1957

9) Birdsall, B.; N. J. M. Birdsall \& J. Feeney: Simplified ${ }^{13} \mathrm{C}$ spectral assignments using a graphical method to present ${ }^{19} \mathrm{C}$ spectra recorded under conditions of proton off-resonance spin decoupling. Chem. Comm. 1972: 316 317, 1972

10) Johnson, L. E. \& W. C. JANKowski: Carbon-13 NMR spectra. Wiley-Interscience, 1972

11) DoLAK, L.: Process for N-acylating novenamine. U.S. Patent No. 3,890,297, June 17, 1975

12) Rodighiero, G. \& C. Antonello: Derivatives of 3-aminocoumarin and their antibacterial activity. Boll. Chim. Farm. 97: 592 601, 1958; Chem. Abstr. 53: 92101a, 1958 